\title{
Heterogeneity of white adipose tissue: molecular basis and clinical implications
}

\author{
Kelvin HM Kwok ${ }^{1,2}$, Karen SL Lam ${ }^{1,2,3}$ and Aimin $\mathrm{Xu}^{1,2,3,4}$ \\ Adipose tissue is a highly heterogeneous endocrine organ. The heterogeneity among different anatomical depots stems from their \\ intrinsic differences in cellular and physiological properties, including developmental origin, adipogenic and proliferative \\ capacity, glucose and lipid metabolism, insulin sensitivity, hormonal control, thermogenic ability and vascularization. Additional \\ factors that influence adipose tissue heterogeneity are genetic predisposition, environment, gender and age. Under obese \\ condition, these depot-specific differences translate into specific fat distribution patterns, which are closely associated with \\ differential cardiometabolic risks. For instance, individuals with central obesity are more susceptible to developing diabetes and \\ cardiovascular complications, whereas those with peripheral obesity are more metabolically healthy. This review summarizes the \\ clinical and mechanistic evidence for the depot-specific differences that give rise to different metabolic consequences, and \\ provides therapeutic insights for targeted treatment of obesity.
}

Experimental \& Molecular Medicine (2016) 48, e215; doi:10.1038/emm.2016.5; published online 11 March 2016

\section{INTRODUCTION}

Owing to the modern sedentary lifestyle in both developed and rapidly developing countries, the prevalence of obesity has reached an alarming level and has become a worldwide epidemic, affecting over 500 million adults and 40 million children. Morbidly obese individuals with body mass index above $35 \mathrm{~kg} \mathrm{~m}^{-2}$ are associated with significantly higher allcause mortality, ${ }^{1,2}$ most of which are related to cardiovascular diseases, diabetes and cancers. ${ }^{2}$

Obesity is characterized by an abnormal and excess accumulation of adipose tissue in the body, and this has stimulated immense research interest on the pathophysiological role of adipose tissue in the development of obesity and its related medical complications. Over the past two decades, the adipose tissue has gradually transformed from merely an inert store for excess lipids into a metabolically active endocrine organ $^{3}$ involved in the regulation of glucose and lipid metabolism, ${ }^{4}$ insulin sensitivity, ${ }^{4}$ inflammatory response, ${ }^{5}$ non-shivering thermogenesis ${ }^{6}$ and vascular endothelial function. ${ }^{7}$ Furthermore, adipose tissue is highly heterogeneous. Each anatomical depot differs in metabolic and hormonal profiles and has different physiological roles. The differential accumulation of specific depots therefore translates into different clinical outcomes. It is well established that abdominal or central obesity is more associated with cardiometabolic diseases compared with peripheral obesity. ${ }^{8,9}$ By providing clinical and basic research evidence, this review aims to discuss the fundamental properties of adipose tissue, which give rise to its heterogeneity, and how these contribute to the resulting clinical outcomes.

\section{BASIC FEATURES OF ADIPOSE TISSUE}

Anatomy

White adipose tissue (WAT) is widely dispersed in humans. Major depots reside in subcutaneous region in the upper (deep and superficial abdominal) and lower body (gluteal-femoral), as well as in the visceral region (omental, mesenteric, mediastinal and epicardial; Figure 1a). Subcutaneous WAT is located under the skin where it acts as a barrier against dermal infection, an insulator to prevent heat loss, and a cushion for protection against external mechanical stress. Visceral WAT in the body trunk is buried around vital organs within the peritoneum and rib cage. With current technological advances, the distribution and accumulation of specific adipose depot can be accurately and quantitatively assessed by regional magnetic

\footnotetext{
${ }^{1}$ State Key Laboratory of Pharmaceutical Biotechnology, University of Hong Kong, Hong Kong, China; ${ }^{2}$ Department of Medicine, University of Hong Kong, Hong Kong, China; ${ }^{3}$ Research Centre for Heart, Brain, Hormones and Healthy Aging, University of Hong Kong, Hong Kong, China and ${ }^{4}$ Department of Pharmacology and Pharmacy, University of Hong Kong, Hong Kong, China

Correspondence: Dr A Xu, Department of Medicine and Department of Pharmacology and Pharmacy, University of Hong Kong, L8-40, Laboratory Block, 21 Sassoon Road, Hong Kong 999077, China.

E-mail: amxu@hku.hk
}

Received 20 November 2015; accepted 29 November 2015 

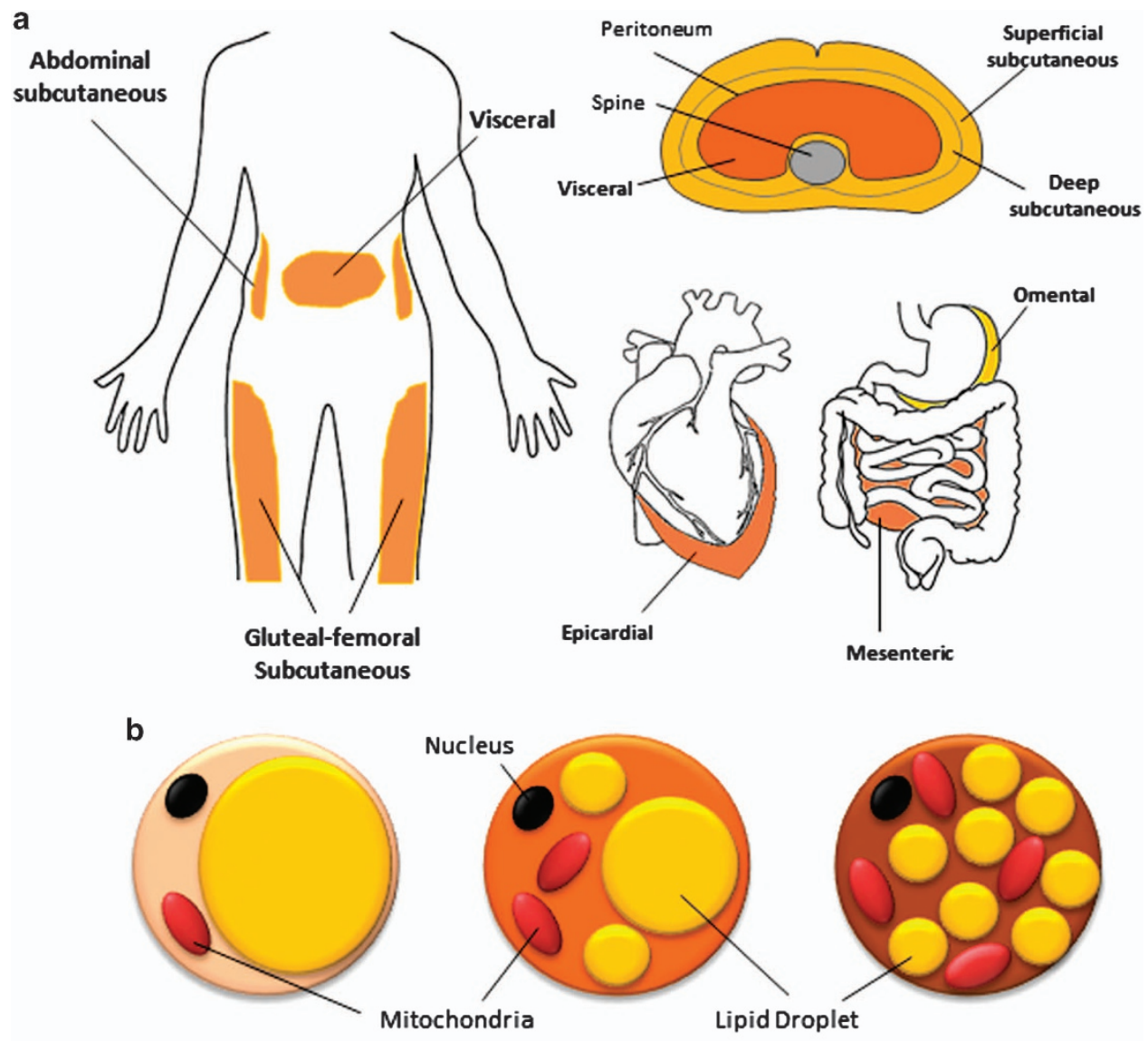

WAT

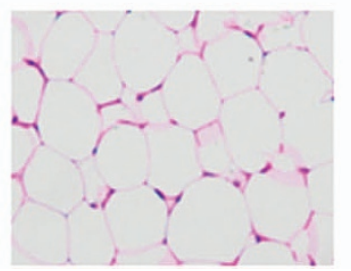

Beige

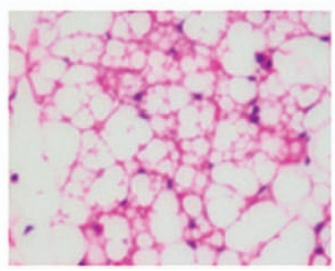

Brown

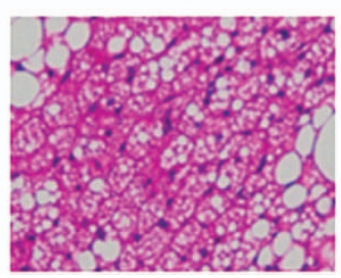

Figure 1 Heterogeneous adipose organ in humans. (a) White adipose tissue (WAT) depots in humans are shown in orange. Major subcutaneous WAT includes superficial and deep abdominal depots and gluteal-femoral depot. Major visceral WAT includes epicardial, omental and mesenteric. (b) Morphological differences between WAT, beige and brown adipose tissue (BAT) adipocytes as shown by cartoon and hematoxylin/eosin staining ( $\times 40$ magnification).

resonance imaging, ${ }^{10}$ computed tomography ${ }^{11}$ and, less frequently, echocardiography ${ }^{12}$ and ultrasonography. ${ }^{13}$

Brown adipose tissue (BAT) is a distinct type of adipose tissue present predominantly in rodents and infant humans located around the scapular. BAT is specialized in utilizing and dissipating the energy derived from lipids to produce heat via the action of uncoupled protein 1 (UCP-1) located in the inner membrane of the mitochondria. ${ }^{6}$ BAT appears brown because of the high mitochondrion content and dense vascularization compared with WAT. In between WAT and BAT is Brite (brown and white) or Beige adipose tissue, which is a subpopulation of WAT that has adopted features of BAT, including increased UCP-1 expression, adipocyte locularity, mitochondrion density and vascularization in a process known as adaptive thermogenesis, or 'browning', upon the stimulation by low temperatures (Figure 1b). ${ }^{14}$ Recently, metabolically active adipose tissue depots with Beige-like characteristics were also found in healthy adult humans at the cervical, supraclavicular, axillary and paravertebral regions. ${ }^{15}$

\section{Energy maintenance in WAT}

The primary function of WAT is to maintain an energy homeostasis. At times of positive energy balance, it uptakes excess lipid and stores it in the form of triglycerides (TGs) to prevent ectopic lipid deposition and adverse metabolic complications as observed in lipodystrophic individuals ${ }^{16}$ and mouse models. ${ }^{17}$ On the other hand, it acts as an energy source and releases lipids in the form of non-esterified fatty acids (NEFAs) when there is a demand for energy. These processes act in concert and respond promptly to different energy states and hormonal cues. 
The uptake of dietary TGs in WAT is mediated by lipoprotein lipase. ${ }^{18}$ These enzymes are attached to the vascular endothelium via highly charged heparin sulphate proteoglycans, with their active sites located at the luminal surface of blood vessels, allowing them to hydrolyze TGs carried by chylomicrons and very-low-density lipoprotein in the bloodstream. With these, NEFA and monoacylglycerol are mobilized and taken up for cellular utilization and storage. ${ }^{18}$ Uptake of hydrolyzed products is mediated by passive diffusion or by fatty-acid translocase/CD36, ${ }^{19}$ caveolin- $1,{ }^{20}$ fatty-acidbinding protein $(\mathrm{FABP})^{21}$ and fatty-acid transport protein. ${ }^{22}$ Finally, these products are trapped via acylation by acyl coenzyme A synthase, ${ }^{23}$ which lowers intracellular NEFA concentrations and favors further uptake, as well as by diacylglycerol acetyltransferase, which performs the committed step in TG synthesis. ${ }^{24}$

Signals for low nutritional state, including catecholamines and sympathetic nervous system, trigger lipolysis in WAT to release NEFA into the circulation. These signals transduce via cyclic AMP and activate protein kinase A, which in turn phosphorylates perilipin A and hormone-sensitive lipase on lipid droplets in adipocytes and promotes lipolysis. Insulin, a signal for high-energy state, inhibits the actions of hormonesensitive lipase by reducing cyclic AMP levels and protein kinase A activity. ${ }^{25}$

The maintenance of energy homeostasis depends not only on the balance between lipid uptake and release, but also on the sensitivity to stimulatory and inhibitory signals mediated by the sympathetic nervous system and hormonal system.

\section{Pathophysiology in obese WAT}

In obesity, WAT depots experience abnormal and excess expansion, either by increase in adipocyte number or adipocyte size. ${ }^{26}$ They become inflamed and release an increased amount of pro-inflammatory cytokines, including monocyte attractant protein 1 , tumor necrosis factor $\alpha$ (TNF- $\alpha$ ), interleukin 6 (IL-6) and adipocyte FABP (A-FABP), and a reduced amount of anti-inflammatory adiponectin into the circulation. ${ }^{27}$ Increased levels of monocyte attractant protein 1 lead to macrophage infiltration into inflamed $\mathrm{WAT}^{28}$ and further exacerbate the low-grade, 'sterile' inflammatory response. Driven by the actions of TNF- $\alpha$ and IL- 6 , inflamed WAT switches from storing to releasing excess NEFAs into the circulation, ${ }^{29}$ causing ectopic lipid deposition and lipotoxicity in vital metabolic organs including the liver and skeletal muscles. ${ }^{30}$ Increased levels of NEFA activate the c-Jun $\mathrm{N}$-terminal kinase pathway via membrane partitioning of c-Src, ${ }^{31}$ which in turn cause insulin resistance through Ser-307 phosphorylation on insulin receptor substrate $1,{ }^{32}$ or inhibition of insulin-stimulated Akt phosphorylation. ${ }^{32}$

\section{CLINICAL EVIDENCE FOR WAT HETEROGENEITY}

\section{Differential predisposition to cardiometabolic diseases}

Several independent studies have reported the paradoxical existence of lean but metabolically obese individuals, ${ }^{33}$ as well as those who are metabolically healthy but obese. ${ }^{34} \mathrm{~A}$ recent study further showed that obese individuals who were metabolically healthy, as categorized according to hepatic TG content and insulin sensitivity, were resistant to adverse cardiometabolic effects following a moderate $(\sim 6 \%)$ weight gain, whereas those who were obese and metabolically abnormal were predisposed. ${ }^{35}$ Increased expression of genes involved in glucose uptake and lipogenesis in subcutaneous depots from metabolically healthy obese individuals was proposed to be one possible explanation for protective lipid diversion and thus different clinical outcomes. ${ }^{35}$ However, the impact of fat distribution on metabolism and the relative contribution of different adipose tissue depots were not further explored in this study. In 1956, Vague reported that central or 'android' obesity was more closely associated with cardiometabolic diseases compared with peripheral or 'gynaecoid' obesity. ${ }^{8}$ In line with this, later cross-sectional and longitudinal studies showed that the waist-to-hip ratio and waist circumference, both indicative of central obesity, were even stronger independent risk factors for insulin resistance, type 2 diabetes, hyperlipidemia and atherosclerosis, as compared with body mass index..$^{9,36}$

\section{Portal Theory}

The 'Portal Theory' proposed that these differential outcomes can be attributed to the unique anatomical locations of particular adipose depots. ${ }^{37}$ In humans, the visceral depots (omental and mesenteric WAT) are drained by the hepatic portal vein into the liver, whereas subcutaneous depots are drained systemically by inferior or superior venae cava. ${ }^{37}$ Whereas NEFAs and pro-inflammatory cytokines released by subcutaneous depots are diluted in the circulation, those released by portal drained visceral depots directly flow to the liver. Thus, individuals with abnormal accumulation of visceral depots are particularly prone to developing hepatic insulin resistance. ${ }^{37} \mathrm{~A}$ fat transplantation study revealed that mice receiving transplantation of portal drained wild-type WAT developed hepatic insulin resistance, but not when receiving IL-6-deficient WAT transplant, ${ }^{38}$ suggesting a significant role of IL-6-mediated NEFA release in this model. Nevertheless, the contribution of NEFAs by visceral WAT depots appears to be insufficient in causing systemic insulin resistance, which is a hallmark of overall metabolic dysfunction. ${ }^{39}$ This is because the upper body subcutaneous depots, but not visceral depots, were shown to be the major source of NEFAs, accounting for up to $70 \%$ of the circulating level in obesity. ${ }^{40}$ Therefore, anatomical location and portal drainage may only represent one of the many factors that give rise to the different association with cardiometabolic risk.

\section{Different origins of WAT depots in human}

Several studies on patients with inherited lipodystrophy have suggested a depot-specific developmental program for adipocytes in humans. ${ }^{16}$ For instance, patients with type 1 congenital generalized lipodystrophy, also known as Berardinelli-Seip lipodystrophy, completely lack adipose tissue, except the mechanical depots in their palms and soles, scalp, 
retro-orbital and peri-articular regions. ${ }^{41}$ Patients with the more common Dunnigan type familial partial lipodystrophy, on the other hand, experience continuous loss of subcutaneous depots in extremities and anterior truncal region, but an excessive fat accumulation in spared locations including the visceral region. ${ }^{42}$ Using microarray and quantitative PCR analysis, Gesta et al. ${ }^{43}$ reported major differences in the expression of a cluster of developmental and patterning genes between subcutaneous and visceral WAT depots taken from humans of both genders. Whereas subcutaneous depot expressed higher levels of Shox2, En1, HoxC9 and Gpc4, visceral depots were more abundant with the transcripts of Sfrp2, Nr2f1, Thbd, HoxA5, HoxC8 and Tbx $15 .{ }^{43}$ In particular, Tbx15, a mesodermal developmental gene, not only showed different expression levels between depots, but also a strong exponential negative relationship between its expression in visceral WAT and waist-to-hip ratio as well as body mass index. ${ }^{43}$ In another study, intrinsic differences between human subcutaneous and visceral WAT depots in the expression of early developmental genes, including homeotic genes, were traced back to yet undifferentiated preadipocytes. ${ }^{44}$ After virtually immortalizing single isolated primary preadipocytes from different depots by stably expressing the telomerase subunit, human telomerase reverse transcriptase, the depotspecific expression profile partially sustained for at least 40 population doublings, ${ }^{44}$ supporting the notion that subcutaneous and visceral WAT depots are intrinsically different. Interestingly, the expression of developmental genes also differed between subcutaneous depots in the abdomen and gluteal region in both lean and obese adults, and that these differences correlated with the extent of DNA methylation of these genes. ${ }^{45}$ Further studies are required to investigate whether the depot-specific developmental programs between subcutaneous and visceral depots are epigenetically regulated and how.

\section{WAT expansion}

Association studies have shown that adipocyte enlargement, but not increase in adipocyte number, is associated with elevated cardiometabolic risks. ${ }^{46}$ Preadipocytes in the stromal vascular fraction from WAT, the largest pool of progenitor cells in humans, are the major progenitor cells that give rise to new adipocytes. In colonies raised from single preadipocyte clones, two subtypes of preadipocytes have been identified, with one being more proliferative, replicative, adipogenic and resistant to TNF- $\alpha$-induced apoptosis, and the other subtype being less so. ${ }^{47}$ Clonal preadipocytes from subcutaneous WAT depots behaved like the former subtype, whereas those from visceral depots displayed characteristics of the latter, in a cellautonomous and inheritable manner, ${ }^{48}$ which is consistent with the findings that peripheral obese individuals are more metabolically healthy. ${ }^{8}$ With overfeeding, abdominal subcutaneous WAT experienced mainly adipocyte enlargement, whereas a massive increase in adipocyte number was observed in the femoral subcutaneous depot. ${ }^{26}$ Adipocyte hypertrophy in omental, but not subcutaneous depot, in obese women was independently associated with dyslipidemia. ${ }^{49}$ On the contrary, Arner et al. ${ }^{50}$ recently showed that adipocyte number rather than cell size strongly correlated with the weight of greater omentum in obese humans, and proposed that omental depot accumulation is mainly determined by the adipocyte proliferation rate.

\section{Lipid metabolism}

Another important factor controlling the rate and extent of expansion of WAT is the regulation of lipid flux in adipocytes. As gender appears to be an important factor in the manifestation of central (android) or peripheral (gynaecoid) obesity, a majority of human studies on lipid metabolism in WAT explored both gender and interdepot differences. The uptake of NEFA in men was increased in abdominal subcutaneous depot compared with femoral depot, although the opposite was observed in women. ${ }^{51}$ In both lean and obese individuals, women were shown to be more efficient in storing lipids in femoral depot than men, likely mediated by higher postprandial activities of local lipoprotein lipase, although the efficiency in abdominal subcutaneous depot was similar. ${ }^{52}$ In support of these findings, the expression of NEFA-transporting proteins, including $\mathrm{CD} 36$ and A-FABP, was higher in the femoral depot in women..$^{51}$ Moreover, northern blotting results showed that the gene transcript of lipoprotein lipase was more abundant in subcutaneous depot than in visceral omental depot in obese women, which was opposite to that found in obese men. ${ }^{53}$ Collectively, these findings suggest that women are in general more efficient in partitioning fat in the periphery compared with men, partly explaining the stereotypical genderspecific fat distribution pattern and hence the typically better metabolic health in women. Interestingly, whereas the insulin responsiveness is higher in omental depot than in subcutaneous depot in lean individuals, as evidenced by intensified and more rapid insulin-induced Akt phosphorylation in the former depot, ${ }^{54}$ the increase in lipoprotein lipase expression in response to insulin in morbidly obese individuals is much greater in subcutaneous depot compared with omental depot without a significant gender effect, ${ }^{53}$ suggesting that there may be a switch in storage pattern and blunted insulin response as obesity develops.

The effects of catecholamines on lipolysis were much greater in omental depot than in subcutaneous depot ${ }^{55}$ because of an increase in pro-lipolytic $\beta$-adrenergic receptor activity ${ }^{56}$ and reduction in anti-lipolytic $\alpha$-adrenergic receptor activity in the former. ${ }^{56}$ These differences were also noted in obese individuals. ${ }^{57}$ Another study reported that the higher basal and adrenaline-stimulated lipolytic rate in abdominal subcutaneous and visceral depots in women with central obesity were less responsive to the suppressive effects of insulin when compared with those with peripheral obesity. ${ }^{58}$ One possible explanation for this is the increased protein-tyrosine phosphatase $1 \mathrm{~B}$ activity in visceral depot compared with subcutaneous depot. ${ }^{59} \mathrm{~A}$ recent lipidomic study that focused on subcutaneous and omental depots in obese human adults revealed depot-specific differences in glycerophospholipid 
levels, degree of saturation of lipid chains and oxysterol accumulation, which likely reflect the differential capacity in adipogenesis, lipolysis and endoplasmic reticulum stress reponse, respectively. ${ }^{60}$ These differences were much smaller in lean individuals, ${ }^{60}$ suggesting a depot-specific lipidomic response to excess WAT accumulation. The effects of sex hormones on WAT heterogeneity in lipid handling have been well documented, ${ }^{61}$ but relatively few studies looked at the effects of ethnicity. ${ }^{58}$

\section{Inflammation}

The depot-specific expression of pro-inflammatory and antiinflammatory cytokines in humans has been extensively reviewed by Lee et al. ${ }^{62}$ Compared with subcutaneous WAT depots, visceral WAT depots in general display a more pro-inflammatory profile ${ }^{62}$ with greater secretory capacity. ${ }^{63}$ Although obesity led to increase in expression of proinflammatory cytokines in both depots, ${ }^{64}$ visceral depot retained its dominance in secreting these cytokines, including IL- $6{ }^{53}$ TNF- $\alpha,{ }^{65}$ IL- $8,{ }^{65}$ C-reactive protein, ${ }^{65}$ complement C $3{ }^{65}$ macrophage migration inhibitory factor ${ }^{66}$ and CC chemokine receptor $2 .{ }^{66}$ Conversely, subcutaneous WAT was shown to express more adiponectin ${ }^{66}$ an adipocyte-derived adipokine that exerts anti-inflammatory and multiple beneficial effects on metabolism, ${ }^{67,68}$ in both lean and obese states, although at a much lower level in the latter. In line with this, several studies showed increased macrophage infiltration in obese visceral depots compared with subcutaneous depots, ${ }^{69}$ whereas others demonstrated elevated mitogen-activated protein kinase- and inhibitory- $\mathrm{\kappa B}$ kinase-mediated inflammatory response predominantly in the visceral depot upon TNF- $\alpha$ stimulation. $^{70,71}$

\section{MECHANISTIC EVIDENCE FOR WAT HETEROGENEITY}

In addition to the mounting evidence from human association studies, accumulating findings from in vitro and in vivo studies in animals provide further mechanistic insights in WAT heterogeneity, which can potentially be translated into therapeutic applications.

\section{Developmental origin and adipogenesis}

Similar to humans, WAT in mice have depot-specific developmental origins, suggesting a possibly conserved developmental program. This is evidenced by the high resemblance in the depot-specific expression profiles of developmental genes between genetically obese $o b / o b$ mice and humans. ${ }^{43,72}$ In a recent study, which applied delicate cell-sorting strategies, varying proportions of adipocytes specifically from visceral depots in mice were found to arise from Wilm's tumor (Wt1)-positive mesothelial progenitors during embryogenesis. ${ }^{73}$ Adipocytes from subcutaneous depot probably originate from other sources of progenitor via different mechanisms. Indeed, low-density lipoprotein-related protein (LRP)-5 of the WNT signaling cascade appears to be a major regulator for fat distribution among subcutaneous depots. In humans, gain of function mutation in the LRP5 allele was associated with fat accumulation in the lower body, better metabolic health and reduced WAT inflammation. ${ }^{74}$ In line with this clinical report, the knockdown of LRP5 by short hairpin RNA severely impaired adipogenesis and increased inflammation through the canonical $\beta$-catenin pathway in SVF isolated from gluteal WAT depot but not from abdominal subcutaneous depot, ${ }^{74}$ partially explaining the predisposition to different fat distribution patterns and cardiometabolic risks. Unlike in mice, ${ }^{75}$ manipulation of LRP5/WNT in these human preadipocytes did not affect insulin signaling. ${ }^{74}$

Another piece of evidence for depot-specific developmental program came from a study on $14-3-3 \zeta$, an adaptor protein involved in metabolic regulation, autophagy and apoptosis. ${ }^{76}$ Mice deficient in 14-3-3 $\zeta$ displayed marked reduction only in visceral depot, which contributed to reduced body weight and fat mass, as well as improved glucose tolerance and insulin sensitivity, whereas overexpression resulted in the opposite effect. $^{77} 14-3-3 \zeta$ was necessary for adipogenesis in visceral WAT, and loss of $14-3-3 \zeta$ led to autophagy-dependent degradation of adipogenic factors and disruption of cell cycle progression. ${ }^{77}$ However, there was no evidence on the temporal control of adipogenesis, and the metabolic consequences in these mice were likely altered by the catch-up growth since the age of $\sim 3$ weeks. ${ }^{77}$ Besides, it is still unclear how subcutaneous depots were spared from the effects of global 14-3-3 $\zeta$ deficiency.

The role of microRNA (miRNA) in WAT development and adipogenesis is well recognized in multiple species including humans, ${ }^{78}$ mice $^{78}$ and bovine. ${ }^{79}$ The depot-specific expression pattern of miRNA has also been implicated in obese $e^{80}$ or diabetic $^{81}$ humans. The processing and maturation of miRNA requires the RNA-processing enzyme Dicer. ${ }^{82}$ The expression of Dicer was previously found to be constantly declining over time in Caenorhabditis elegans as well as in subcutaneous WAT of mice, likely because of calorie intake and aging. ${ }^{83}$ A follow-up study using mice with adipose-specific deficiency in Dicer clearly showed depot-specific effects of miRNA dysregulation on the development and metabolism of WAT, which were exacerbated when challenged by high-fat diet. ${ }^{84}$ The authors successfully identified miRNAs that were responsible for the drastic phenotypes globally (miR346 and miR362) and in BAT (miR-365). ${ }^{84}$ It is reasonable to speculate the existence of depot-specific expression profile and even secretion pattern of miRNAs, which orchestrate the complex development and endocrine function of the adipose organ.

Although it was shown in obese humans that hypertrophy occurred in visceral WAT while hyperplasia was predominant in subcutaneous WAT, 85 two recent independent studies showed a different scenario in mice. ${ }^{86,87}$ Wang et al. ${ }^{86}$ developed a triple transgenic, 'Adipochaser' mouse model that utilizes adipose-specific Cre-loxP- and LacZ-doxycyclineinducible systems to monitor the development and adipogenesis of WAT at a cellular level. The authors found that adipocytes in visceral depot started the differentiation process postnatally, whereas those in subcutaneous depot differentiated during prenatal stage at a slower rate and completed well after 
birth. ${ }^{86}$ The expansion of WAT initially occurred through hypertrophy in both depots in response to high-fat diet, but switched to hyperplasia after $\sim 1$ month only in the visceral depot. ${ }^{86}$ This seemed counterintuitive as hyperplasia is linked to more healthy expansion of WAT, although visceral depot expansion is metabolically detrimental. Similarly, a tamoxifeninducible adipocyte-tracking mouse model showed a rapid but transient induction of adipocyte precursor proliferation and Akt2-dependent differentiation only in visceral WAT depot from diet-induced obese or $o b / o b$ mice, which resulted in an increased adipocyte number not observed in subcutaneous depot. ${ }^{87}$ On the contrary, Macotela et al. ${ }^{88}$ found that despite there are more adipocyte precursor cells in the SVF from visceral depot, those in subcutaneous depot seemed to have a greater potential to differentiate in response to classical induction cocktail than in visceral depot, which required bone morphogenetic protein (BMP)-2 or BMP-4 supplementation to achieve similar effects. However, the pathological relevance in these in vitro-based findings remained to be validated. Currently, the precise mechanism of depot-specific activation of adipocyte precursor cells is still poorly understood, and the effects of hyperplasia or hypertrophy on metabolic parameters such as insulin sensitivity remain unclear. More studies are needed to reveal the significance of cellular heterogeneity in WAT in these aspects.

\section{Metabolism}

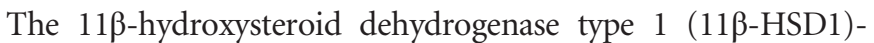
deficient mouse is a classic model to demonstrate a healthier fat accumulation pattern and improved metabolism driven by depot-specific mechanisms. ${ }^{89}$ Upon feeding with high-fat diet, subcutaneous WAT of 11 $\beta$-HSD1-deficient mice displayed increased expansion, better insulin sensitivity and reduced adipocyte hypertrophy, whereas visceral depots had increased AMPK activity and decreased infiltration of macrophage and T lymphocyte, but not dramatic changes in volume. ${ }^{89}$

Whole-adipose-tissue transplantation in mice allows the assessment of metabolic properties of isolated WAT depots (Figure 2). Konrad et $a .^{90}$ reported that intraperitoneal transplantation of lean visceral depot into C57B6/J mice improved, rather than impaired, glucose tolerance and insulin sensitivity, suggesting that the functionality of WAT, rather than anatomical location or fat mass, is the major determinant for the association with different metabolic risks. In contrast, other groups have shown that the intraperitoneal transplantation of subcutaneous depot instead of visceral depot conferred metabolic benefits in the recipient mice. ${ }^{91-93}$ The transplantation of subcutaneous depot into the visceral cavity of obese mice also improved hepatic insulin sensitivity. ${ }^{94}$ Another transplantation study showed that the removal of visceral depot or intraperitoneal implantation of visceral depot protected rats from aging-related glucose intolerance. ${ }^{95}$ This was achieved through enhanced insulin secretion and transient induction of fasting leptin level to improve insulin sensitivity. ${ }^{95}$ It would be interesting to see whether transplanting visceral depot will have any effects on aging mice. The underlying mechanisms of transplantation-mediated metabolic changes are still incompletely understood. All of the above studies noted changes in glucose metabolism or insulin sensitivity, but none reported alterations in lipid profile or metabolism, suggesting that fat graft did not simply act as an extra lipid reservoir. Although leptin was shown to be essential in rescuing the metabolic dysfunction in lipoatrophic A-ZIP/F-1 mice that received fat transplantation, ${ }^{96}$ evidence for its contribution in the above depot-specific metabolic effects is limited and inconsistent. ${ }^{92,95}$ Collectively, these transplantation studies generally support a cell-autonomous beneficial role of subcutaneous depots in the overall metabolism, but the molecular basis remains poorly understood.

\section{Inflammation}

WAT macrophages are subjected to phenotypic polarization in obesity, resulting in an increase in classically activated, proinflammatory M1 macrophages and reduction in alternatively activated, anti-inflammatory M2 macrophages. ${ }^{97}$ However, this process appears to occur in different extents and through different mechanisms in various WAT depots.

Fyn is a Src family non-tyrosine kinase with a wide range of biological functions, participating in immunological ${ }^{98}$ and metabolic processes. ${ }^{99}$ Mice deficient in Fyn were not protected against diet-induced obesity. Instead, they exhibited preferential fat partitioning into the subcutaneous depots and, intriguingly, improved lipid profile, glucose tolerance, insulin sensitivity and reduced systemic inflammation. ${ }^{100}$ There was less macrophage infiltration and increased M2/M1 ratio in visceral WAT, which were accompanied by reduced infiltration of T lymphocytes. ${ }^{100}$ This finding demonstrates a possible crosstalk between WAT depots, where, in the absence of Fyn, excess lipids were redirected to subcutaneous depots, which experienced a healthier expansion, sparing the less healthy visceral depots from developing inflammation due to lipid accumulation.

Interferon regulatory factor 5 (IRF5), another major factor in the immune system, has been implicated $\mathrm{T}_{\mathrm{H}} 17$ response ${ }^{101}$, which was observed in inflamed WAT from obese humans and mice. ${ }^{102}$ Interestingly, IRF5 expression was selectively induced in macrophages in obese visceral depots and continued to rise over time. ${ }^{103}$ Knocking out IRF5 both globally and selectively in macrophages promoted M2 polarization and antiinflammatory response selectively in visceral WAT, and on the other hand stimulated adiposity in subcutaneous WAT. ${ }^{103}$ Concomitantly, glucose tolerance and insulin sensitivity were restored in IRF5-deficient mice. ${ }^{103}$ The metabolic actions of Fyn and IRF5 may share similar pathways as the deficiency in either protein led to similar fat-partitioning and metabolic improvement through macrophage polarization. The adaptor protein $14-3-3 \zeta$ is known to regulate monocyte migration upon redox metabolic priming ${ }^{104}$ and macropinocytosis for the modulation of macrophage-related inflammatory response. ${ }^{105}$ It would be interesting to investigate whether 14-3-3 $\zeta$ modulates metabolism by having a role in macrophage infiltration and polarization in WAT, in addition to its contribution in WAT development. ${ }^{77}$ MitoNEET, a membrane 


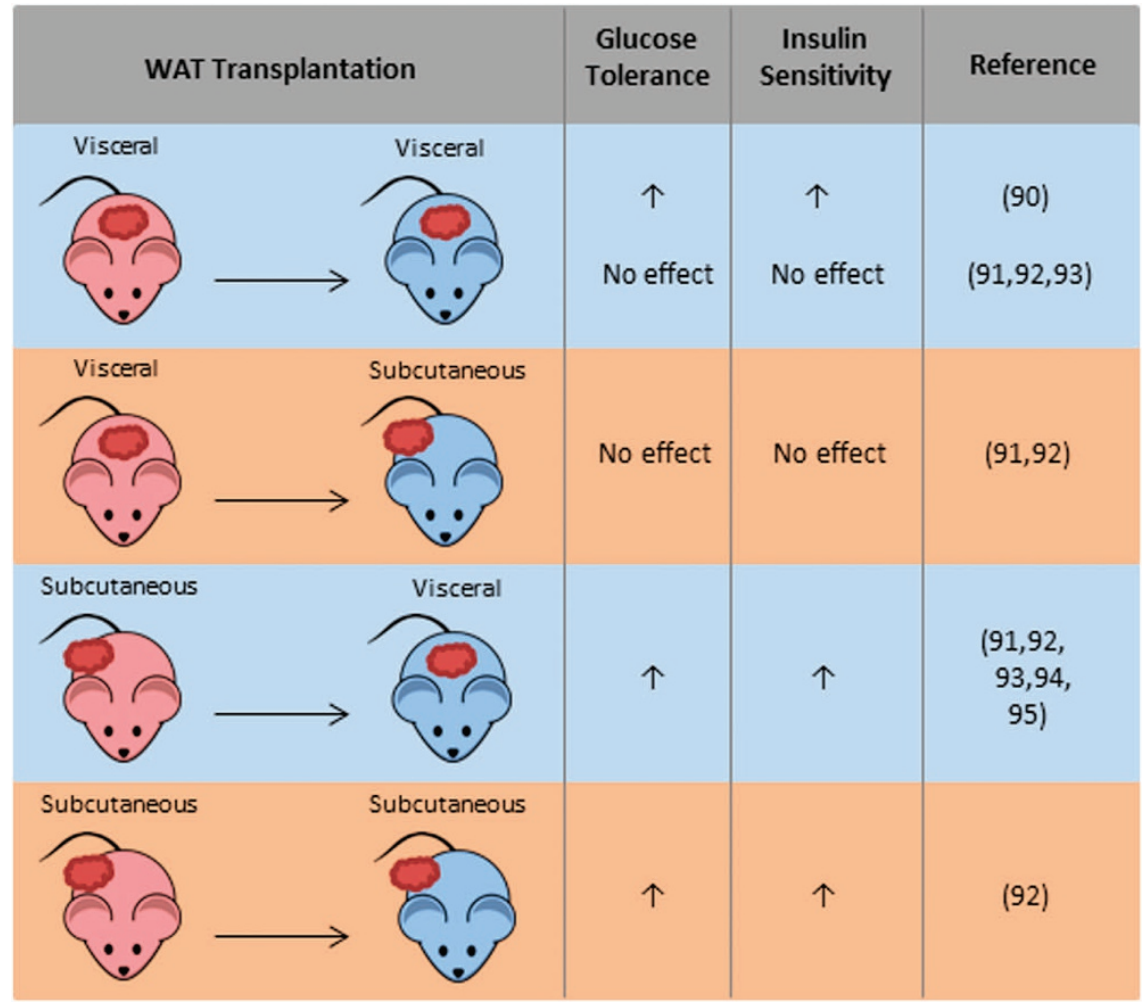

Figure 2 Impacts of fat transplantation on metabolism and insulin sensitivity in mice. Subcutaneous or visceral depots from donor mice were transplanted subcutaneously or intraperitoneally into recipient mice, which were then assessed for glucose tolerance and insulin sensitivity.

protein located in the outer mitochondrial membrane, was also shown to modulate the polarization of macrophages in WAT with depot specificity. ${ }^{106}$ When overexpressed in WAT, it reduced macrophage infiltration and stimulated M2 polarization selectively in subcutaneous depot, ${ }^{106}$ where it also improved insulin response and promoted lipid uptake. ${ }^{106,107}$

The importance of $\mathrm{T}$ lymphocytes in the development of obesity is being increasingly recognized. Recently, adipocyte class II major histocompatibility complex-dependent activation of CD4+ T cell was reported to drive adipose tissue inflammation upon high-fat diet treatment, which surprisingly preceded the actions of macrophages. ${ }^{108}$ Signal transducer and activator of transcription 3 in $\mathrm{T}$ cells was responsible for the high $\mathrm{T}$ helper $1 / \mathrm{Foxp}^{+} \mathrm{T}$ regulatory ratio and the resultant proinflammatory response in obese adipose tissue, at least in the visceral depot. ${ }^{109}$ The accumulation of Foxp $3^{+} \mathrm{T}$ regulatory cells in visceral depots was further explored in lean aging mice. ${ }^{110}$ However, evidence for these processes in subcutaneous depot is relatively scarce; thus, it is unknown whether the reduced inflammatory state in this depot is due to an inversely skewed T-cell response.

Intriguingly, despite the mounting evidence demonstrating a deleterious role of adipose tissue inflammation in metabolic syndrome, this response seems to exert paradoxically beneficial effects on the expansion of adipose tissue challenged with highfat diet, again with interdepot differences. ${ }^{111}$ This raises the possibility that the magnitude and duration of inflammatory response rather than its nature is more important in obese adipose tissue.

\section{Browning}

Browning is the development of thermogenic Beige cells in WAT in response to environmental stimuli such as low temperatures, exercise and treatment with peroxisome proliferator-activated receptor $\gamma$ (PPAR $\gamma)$ agonists. ${ }^{12}$ WAT browning positively correlates with improved overall metabolism as a consequence of increased energy expenditure and insulin sensitivity, and weight loss. ${ }^{112}$ It is widely accepted that browning occurs almost exclusively in the subcutaneous depots of WAT, ${ }^{112}$ which supports the notion that subcutaneous WAT confers more metabolic benefits. PRDM16, a transcription co-regulator responsible for brown adipocyte development in classic BAT depot, ${ }^{113}$ has unique roles that distinguish subcutaneous WAT from visceral WAT in browning capacity. Compared with visceral WAT, PRDM16 was highly expressed in subcutaneous WAT, where its overexpression markedly promoted browning in a cell-autonomous manner ${ }^{114}$ likely through de novo adipogenesis. ${ }^{86}$ Conversely, lack of PRDM16 sharply reduced the extent of browning in subcutaneous WAT. ${ }^{114,115}$ The browning effects mediated by PPAR $\gamma$ agonist rosiglitazone also required PRDM16 specifically in subcutaneous WAT. ${ }^{116}$ Further studies are required to unveil whether other factors involved in browning, including UCP-1 and PPAR $\gamma$ co-activator $1-\alpha$ (PGC- $1 \alpha$ ), share similar 


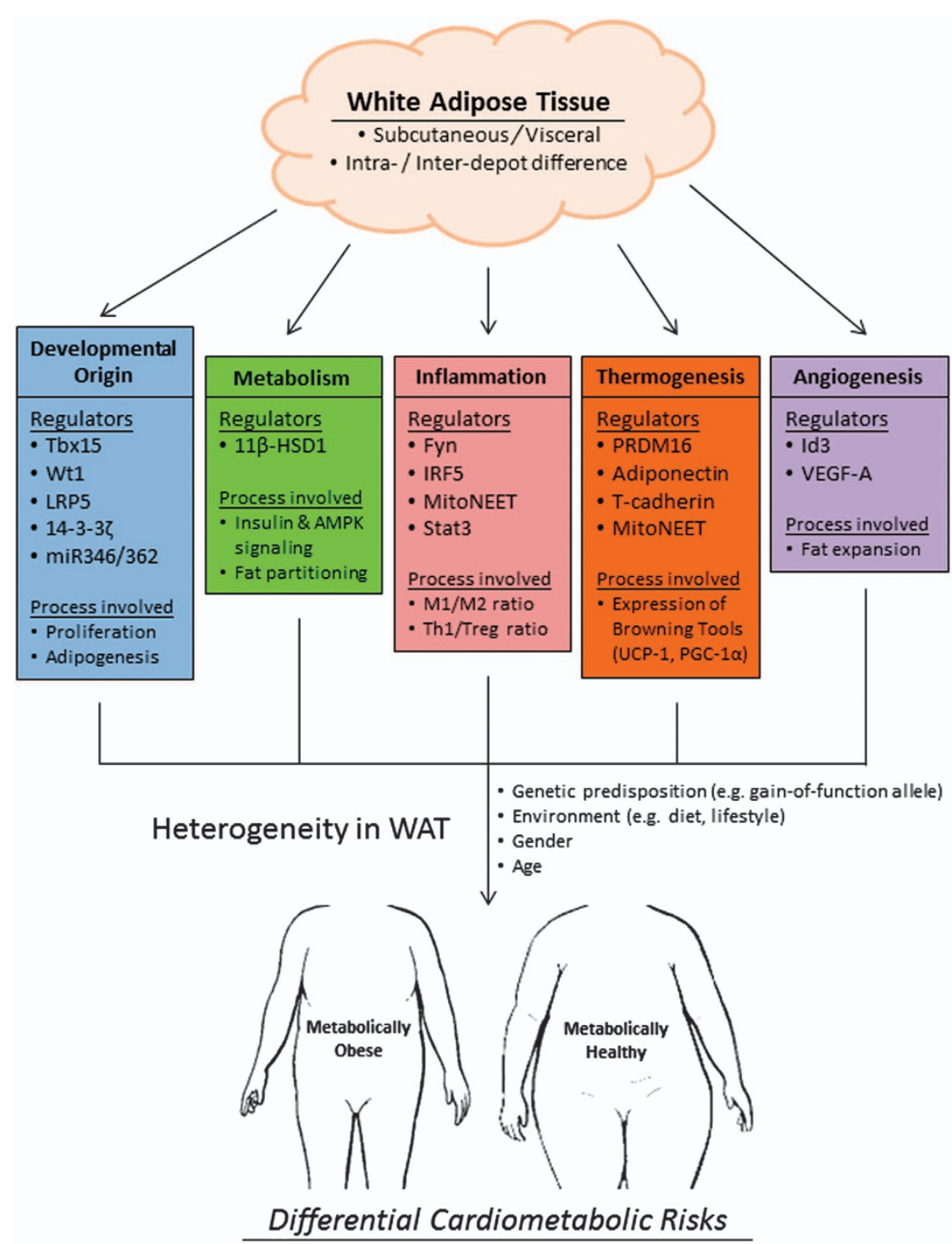

Figure 3 Currently identified regulators and processes that give rise to heterogeneity in white adipose tissue (WAT) which, together with environmental factors, in turn contribute to differential cardiometabolic risks.

depot-specific regulatory network. Notably, gene expression profiling and lineage studies using immortalized adipocytes showed that thermogenic genes not only display an interdepot variation, but also intradepot difference, giving rise to subpopulations of adipocytes with greater browning capacities within the same subcutaneous depot. ${ }^{117}$

M2 macrophages promote WAT browning in mice by inducing catecholamine production, and the expression of tyrosine hydroxylase and thermogenic machineries, including UCP-1 and PRDM16. ${ }^{118-120}$ The depot-specific browning capacity may arise from the marked induction of adiponectin expression selectively in subcutaneous WAT, which in turn stimulated the local de novo proliferation of M2 macrophages. ${ }^{120}$ The crucial actions of adiponectin were assisted by elevated local levels of T-cadherin, ${ }^{120}$ a glycoprotein anchored on the plasma membrane that facilitates the intracellular trapping of adiponectin. ${ }^{121,122}$ In line with these, overexpression of mitoNEET in WAT caused a selective upregulation of adiponectin expression in the subcutaneous depot, which was accompanied by M2 macrophage polarization and increased browning. ${ }^{106,107}$ It is unclear how the expression of adiponectin is controlled in different WAT depots, but epigenetic regulation is a highly possible mechanism, as it was recently shown that obesity-induced cytokine production in visceral WAT suppressed the expression of adiponectin via DNA methylation at its promoter region. ${ }^{123}$

\section{Angiogenesis}

As with other organs, the expansion of WAT requires angiogenesis, ${ }^{124}$ stimulated either through metabolic and developmental cues or by hypoxic signals due to adipocyte hyperplasia and hypertrophy. Angiogenesis is implicated in the pathogenic expansion of WAT in humans, which leads to cardiometabolic diseases. ${ }^{125}$ Indeed, visceral adiposity was 
associated with elevated serum levels of vascular endothelial growth factor in humans. ${ }^{126}$ Inhibitor of differentiation 3 (Id3), a helix-loop-helix factor that regulates tumor and angiogenesis, ${ }^{127}$ was found to have a role in high-fat-dietinduced angiogenesis, specifically in the visceral depots in mice, ${ }^{128}$ through unknown mechanisms. Deficiency in Id3 abolished the upregulation of vascular endothelial growth factor-A expression in obese visceral WAT and resulted in reduced weight gain. ${ }^{128}$

\section{THERAPEUTIC APPROACHES TARGETING WAT HETEROGENEITY}

A majority of current antiobese strategies, including lifestyle intervention, ${ }^{129}$ drug treatment, ${ }^{130}$ exercise and metabolic surgery, ${ }^{131}$ reduces overall obesity without targeting any particular depot. These approaches either have compliance problem or adverse side effects, or they fail to combat weight regain. In other cases, a direct physical removal of subcutaneous fat is performed by liposuction and cosmetic surgery. However, lipectomy of subcutaneous WAT may induce subsequent enlargement in the visceral depot, ${ }^{132}$ which can be more damaging to the metabolism. Although intriguing, increased peripheral adiposity may not always be harmful to metabolism. In fact, an expansion of subcutaneous WAT, particularly in the lower body, can perhaps be beneficial to individuals with visceral adiposity, at least in terms of insulin sensitivity, as supported by the human and animal studies above. Thus, a region-specific healthy expansion of adipose tissue or fat distribution remodeling mediated by PPAR $\gamma$ agonists or 11 $\beta$-HSD1 inhibitors might be the choice of therapy for obesity. These have been proven efficacious at least in rats. ${ }^{133,134}$ However, it cannot be neglected that morbid peripheral obesity, despite metabolically healthy, still correlates with increased mortality. ${ }^{1,2}$

WAT browning is a promising therapeutic strategy in combating obesity owing to its efficacious outcomes as evidenced by a recent human study. ${ }^{135}$ Pharmacological agents that promote WAT browning in animal or cell models include sympathetic activators, prostaglandins, natriuretic peptides, retinoids, thyroid hormones, AMPK activators, fibroblast growth factor 21 (FGF21) and BMPs. ${ }^{136}$ Although their efficacy may appear encouraging in animal models, these agents were developed only recently and shall require further investigations to avoid any possible adverse effects in humans. The recent mechanistic evidence that explains the depot-specific origin and activation of Beige adipocytes forms a strong foundation for the development of potent targeted therapies with fewer side effects.

Adipose angiogenesis, on the other hand, has recently become a popular target for treating obesity. ${ }^{125}$ It is generally believed that inhibition of angiogenesis in adipose tissue can limit its growth, and hence alleviate obesity and the related complications. However, this may selectively limit the protective buffering effect of the healthier subcutaneous adipose tissue because of its greater angiogenic ability ${ }^{137}$ and hence a higher sensitivity to inhibition. Furthermore, it may cause hypoxia in adipose tissues, which will exacerbate the inflammatory response, leading to a futile cycle. Depot-specific manipulation of angiogenesis via targets such as Id3 may therefore be an alternative approach to achieve a healthy fat partitioning and improved metabolism.

\section{CONCLUDING REMARKS}

WAT is a highly heterogeneous organ. Depot-specific differences are present in rodents, rabbits, guinea pigs, humans and other mammals, indicating a strong evolutionary advantage. The apparent compartmentalization of adipose tissue in the body roots from the differential developmental origin of the precursor cells in different and within depots. This inter- and intradepot heterogeneity is gradually amplified during WAT expansion by cell-autonomous differences in the dynamic turnover of adipocytes, regulation of lipid flux and metabolism and also cytokine profile. All these factors are influenced by genetic predisposition, environment, gender and age. Together, they define the tendency and mode of the development of obesity, which in turn determine the susceptibility to a range of cardiometabolic diseases (Figure 3). Finally, it should be noted that the adipose organ has been grossly categorized into subcutaneous and visceral depots to fit the scope of this review, and does not entirely reflect the real situation in animals or humans. In particular, the unique anatomical and physiological roles of epicardial ${ }^{138}$ and perivascular adipose tissue, ${ }^{139}$ two subdepots of visceral fat, have further contributed to the complex concept of depot specificity of WAT.

Further studies to refine current knowledge on the heterogeneity of WAT are required before the clinical implementation of WAT depot-specific therapies to combat obesity-related cardiometabolic diseases. In particular, prospective studies that examine the association between each of the fat depot and cardiovascular risks will help to define the roles of each individual fat depot in the onset and/or progression of the diseases. In addition, further genetic and biochemical manipulation of the identified key factors that give rise to the heterogeneity in WAT may provide further mechanistic insights on the origin, development and physiological functions of each WAT depot.

\section{CONFLICT OF INTEREST}

The authors declare no conflict of interest.

\section{ACKNOWLEDGEMENTS}

This study is supported by the French National Research Agency (ANR)/Research Grants Council (RGC) Joint Research Scheme (A-HKU705/13), RGC/Collaborative Research Fund (C7055-14G) and matching grant for the State Key Laboratory of Pharmaceutical Biotechnology from the University of Hong Kong.

1 Flegal KM, Kit BK, Orpana H, Graubard BI. Association of all-cause mortality with overweight and obesity using standard body mass index categories: a systematic review and meta-analysis. JAMA 2013; 309: 71-82.

2 Kitahara CM, Flint AJ, de Gonzalez AB, Bernstein L, Brotzman M, Maclnnis RJ et al. Association between class III obesity (BMI of 
40-59 $\mathrm{kg} \mathrm{m}^{-2}$ ) and mortality: a pooled analysis of 20 prospective studies. PLoS Med 2014; 11: e1001673.

3 Kershaw EE, Flier JS. Adipose tissue as an endocrine organ. J Clin Endocrinol Metab 2004; 89: 2548-2556.

4 Saltiel AR, Kahn CR. Insulin signalling and the regulation of glucose and lipid metabolism. Nature 2001; 414: 799-806.

5 Tilg $\mathrm{H}$, Moschen AR. Adipocytokines: mediators linking adipose tissue, inflammation and immunity. Nat Rev Immunol 2006; 6: 772-783.

6 Cannon B, Nedergaard J. Brown adipose tissue: function and physiological significance. Physiol Rev 2004; 84: 277-359.

7 Chudek J, Wiêcek A. Adipose tissue, inflammation and endothelial dysfunction. Pharmacol Rep 2006; 58: 81-88.

8 Vague J. The degree of masculine differentiation of obesities: a factor determining predisposition to diabetes, atherosclerosis, gout, and uric calculous disease. Am J Clin Nutr 1956; 4: 20-34.

9 Coutinho T, Goel K, Correa de Sa D, Kragelund C, Kanaya AM, Zeller M et al. Central obesity and survival in subjects with coronary artery disease: a systematic review of the literature and collaborative analysis with individual subject data. J Am Coll Cardiol 2011; 57: 1877-1886.

10 Sharma RC. Quantitation and localization of regional body fat distribution -a comparison between magnetic resonance imaging and somatometry. Obes Res 1996; 4: 167-178.

11 Zamboni M, Armellini F, Milani MP, Todesco T, De Marchi M, Robbi R et al. Evaluation of regional body fat distribution: comparison between W/H ratio and computed tomography in obese women. J Intern Med 1992; 232: 341-347.

12 lacobellis G, Assael F, Ribaudo MC, Zappaterreno A, Alessi G, Di Mario U et al. Epicardial fat from echocardiography: a new method for visceral adipose tissue prediction. Obes Res 2003; 11: 304-310.

13 Wagner DR. Ultrasound as a tool to assess body fat. J Obes 2013; 2013 : 280713.

14 Harms M, Seale P. Brown and beige fat: development, function and therapeutic potential. Nat Med 2013; 19: 1252-1263.

15 Nedergaard J, Bengtsson T, Cannon B. Unexpected evidence for active brown adipose tissue in adult humans. Am J Physiol Endocrinol Metab 2007; 293: E444-E452.

16 Fiorenza CG, Chou SH, Mantzoros CS. Lipodystrophy: pathophysiology and advances in treatment. Nat Rev Endocrinol 2011; 7: 137-150.

17 Savage DB. Mouse models of inherited lipodystrophy. Dis Model Mech 2009; 2: 554-562.

18 Goldberg IJ. Lipoprotein lipase and lipolysis: central roles in lipoprotein metabolism and atherogenesis. J Lipid Res 1996; 37: 693-707.

19 Abumrad NA, El-Maghrabi MR, Amri E, Lopez E, Grimaldi P. Cloning of a rat adipocyte membrane protein implicated in binding or transport of longchain fatty acids that is induced during preadipocyte differentiation. Homology with human CD36. J Biol Chem 1993; 268: 17665-17668.

20 Trigatti BL, Anderson RG, Gerber GE. Identification of caveolin-1 as a fatty acid binding protein. Biochem Biophys Res Commun 1999; 255: 34-39.

21 Glatz JF, van der Vusse GJ. Intracellular transport of lipids. Mol Cell Biochem 1989; 88: 37-44.

22 Schaffer JE, Lodish HF. Expression cloning and characterization of a novel adipocyte long chain fatty acid transport protein. Cell 1994; 79: 427-436.

23 Ellis JM, Frahm JL, Li LO, Coleman RA. Acyl-coenzyme A synthetases in metabolic control. Curr Opin Lipidol 2010; 21: 212-217.

24 Yen C-LE, Stone SJ, Koliwad S, Harris C, Farese RV. Thematic review series: glycerolipids. DGAT enzymes and triacylglycerol biosynthesis. J Lipid Res 2008; 49: 2283-2301.

25 Zechner R, Zimmermann R, Eichmann TO, Kohlwein SD, Haemmerle G, Lass $A$ et al. FAT SIGNALS-lipases and lipolysis in lipid metabolism and signaling. Cell Metab. 2012; 15: 279-291.

26 Tchoukalova YD, Votruba SB, Tchkonia T, Giorgadze N, Kirkland JL, Jensen MD. Regional differences in cellular mechanisms of adipose tissue gain with overfeeding. Proc Natl Acad Sci USA 2010; 107: 18226-18231.

27 Gregor MF, Hotamisligil GS. Inflammatory mechanisms in obesity. Annu Rev Immunol 2011; 29: 415-445.

28 Kanda H, Tateya S, Tamori Y, Kotani K, Hiasa K-i, Kitazawa R et al. MCP-1 contributes to macrophage infiltration into adipose tissue, insulin resistance, and hepatic steatosis in obesity. J Clin Invest 2006; 116: 1494-1505.

29 Boden G. Obesity and free fatty acids. Endocrinol Metab Clin North Am 2008; 37: 635-646.

30 Shulman GI. Ectopic fat in insulin resistance, dyslipidemia, and cardiometabolic disease. N Eng J Med 2014; 371: 1131-1141.
31 Holzer RG, Park E-J, Li N, Tran H, Chen M, Choi C et al. Saturated fatty acids induce $\mathrm{c}$-Src clustering within membrane subdomains, leading to JNK activation. Cell 2011; 147: 173-184.

32 Lee YH, Giraud J, Davis RJ, White MF. c-Jun N-terminal Kinase (JNK) mediates feedback inhibition of the insulin signaling cascade. $J$ Biol Chem 2003; 278: 2896-2902.

33 Ruderman N, Chisholm D, Pi-Sunyer X, Schneider S. The metabolically obese, normal-weight individual revisited. Diabetes 1998; 47: 699-713.

34 Primeau V, Coderre L, Karelis AD, Brochu M, Lavoie ME, Messier V et al. Characterizing the profile of obese patients who are metabolically healthy. Int J Obes (Lond) 2011; 35: 971-981.

35 Fabbrini E, Yoshino J, Yoshino M, Magkos F, Luecking CT, Samovski D et al. Metabolically normal obese people are protected from adverse effects following weight gain. J Clin Invest 2015; 125: 787.

36 Bray GA, Jablonski KA, Fujimoto WY, Barrett-Connor E, Haffner S, Hanson RL et al. Relation of central adiposity and body mass index to the development of diabetes in the Diabetes Prevention Program. Am J Clin Nutr 2008; 87: 1212-1218.

37 Item F, Konrad D. Visceral fat and metabolic inflammation: the portal theory revisited. Obes Rev 2012; 13: 30-39.

38 Rytka JM, Wueest S, Schoenle EJ, Konrad D. The portal theory supported by venous drainage-selective fat transplantation. Diabetes 2011; 60: 56-63.

39 Jensen MD. Is visceral fat involved in the pathogenesis of the metabolic syndrome? Human model. Obesity 2006; 14: 20S-24S.

40 Nielsen S, Guo Z, Johnson CM, Hensrud DD, Jensen MD. Splanchnic lipolysis in human obesity. J Clin Invest 2004; 113: 1582-1588.

41 Seip M, Trygstad O. Generalized lipodystrophy, congenital and acquired (lipoatrophy). Acta Paediatr 1996; 85: 2-28.

42 Dunnigan M, Cochrane M, Kelly A, Scott J. Familial lipoatrophic diabetes with dominant transmission. QJM 1974; 43: 33-48.

43 Gesta S, Blüher M, Yamamoto Y, Norris AW, Berndt J, Kralisch S et al. Evidence for a role of developmental genes in the origin of obesity and body fat distribution. Proc Natl Acad Sci USA 2006; 103: 6676-6681.

44 Tchkonia T, Lenburg M, Thomou T, Giorgadze N, Frampton G, Pirtskhalava $T$ et al. Identification of depot-specific human fat cell progenitors through distinct expression profiles and developmental gene patterns. Am J Physiol Endocrinol Metab 2009; 292: E298-E307.

45 Pinnick KE, Nicholson G, Manolopoulos KN, McQuaid SE, Valet P, Frayn $\mathrm{KN}$ et al. Distinct developmental profile of lower-body adipose tissue defines resistance against obesity-associated metabolic complications. Diabetes 2014; 63: 3785-3797.

46 Lundgren M, Svensson M, Lindmark S, Renström F, Ruge T, Eriksson JW. Fat cell enlargement is an independent marker of insulin resistance and 'hyperleptinaemia'. Diabetologia 2007; 50: 625-633.

47 Tchkonia T, Tchoukalova YD, Giorgadze N, Pirtskhalava T, Karagiannides I, Forse RA et al. Abundance of two human preadipocyte subtypes with distinct capacities for replication, adipogenesis, and apoptosis varies among fat depots. Am J Physiol Endocrinol Metab 2005; 288: E267-E277.

48 Tchkonia T, Giorgadze N, Pirtskhalava T, Thomou T, DePonte M, Koo A et al. Fat depot-specific characteristics are retained in strains derived from single human preadipocytes. Diabetes 2006; 55: 2571-2578.

49 Veilleux A, Caron-Jobin M, Noël S, Laberge PY, Tchernof A. Visceral adipocyte hypertrophy is associated with dyslipidemia independent of body composition and fat distribution in women. Diabetes 2011; 60: 1504-1511.

50 Arner $\mathrm{P}$, Andersson DP, Thörne A, Wirén M, Hoffstedt J, Näslund E et al. Variations in the size of the major omentum are primarily determined by fat cell number. The J Clin Endocrinol Metab 2013; 98: E897-E901.

51 Koutsari C, Ali AH, Mundi MS, Jensen MD. Storage of circulating free fatty acid in adipose tissue of postabsorptive humans: quantitative measures and implications for body fat distribution. Diabetes 2011; 60: 2032-2040.

52 Shadid S, Koutsari C, Jensen MD. Direct free fatty acid uptake into human adipocytes in vivo: relation to body fat distribution. Diabetes 2007; 56 : 1369-1375.

53 Fried SK, Bunkin DA, Greenberg AS. Omental and subcutaneous adipose tissues of obese subjects release interleukin-6: depot difference and regulation by glucocorticoid. J Clin Endocrinol Metab 1998; 83: 847-850.

54 Lundgren M, Burén J, Ruge T, Myrnäs T, Eriksson JW. Glucocorticoids down-regulate glucose uptake capacity and insulin-signaling proteins in omental but not subcutaneous human adipocytes. J Clin Endocrinol Metab 2013; 89: 2989-2997. 
55 Hoffstedt J, Arner P, Hellers G, Lönnqvist F. Variation in adrenergic regulation of lipolysis between omental and subcutaneous adipocytes from obese and non-obese men. J Lipid Res 1997; 38: 795-804.

56 Arner P. Catecholamine-induced lipolysis in obesity. Int J Obes (Lond) 1999; 23: 10-13.

57 Van Harmelen V, Lönnqvist F, Thörne A, Wennlund A, Large V, Reynisdottir $S$ et al. Noradrenaline-induced lipolysis in isolated mesenteric, omental and subcutaneous adipocytes from obese subjects. Int $J$ Obes (Lond) 1997; 21: 972-979.

58 Dowling HJ, Fried SK, Pi-Sunyer FX. Insulin resistance in adipocytes of obese women: effects of body fat distribution and race. Metabolism 1995; 44: 987-995.

59 Wu X, Hoffstedt J, Deeb W, Singh R, Sedkova N, Zilbering A et al. Depot-specific variation in protein-tyrosine phosphatase activities in human omental and subcutaneous adipose tissue: a potential contribution to differential insulin sensitivity. J Clin Endocrinol Metab 2001; 86: $5973-5980$

60 Jové M, Moreno-Navarrete JM, Pamplona R, Ricart W, Portero-Otín M, Manuel Fernández-Real J. Human omental and subcutaneous adipose tissue exhibit specific lipidomic signatures. FASEB J 2013; 28: 1071-1081.

61 Santosa S, Jensen MD. The sexual dimorphism of lipid kinetics in humans. Front Endocrinol (Lausanne) 2015; 6: 103.

62 Lee M-J, Fried SK. Depot-specific biology of adipose tissues: links to fat distribution and metabolic risk. In: Leff T, Granneman JG (eds). Adipose Tissue in Health and Disease. Wiley-VCH Verlag GmbH \& Co. KGaA: Weinheim, Germany, 2010, pp 283-306.

63 Hocking SL, Wu LE, Guilhaus M, Chisholm DJ, James DE. Intrinsic depot-specific differences in the secretome of adipose tissue, preadipocytes, and adipose tissue-derived microvascular endothelial cells. Diabetes 2010; 59: 3008-3016.

64 Dolinková M, Dostálová I, Lacinová Z, Michalský D, Haluzíková D, Mráz M et al. The endocrine profile of subcutaneous and visceral adipose tissue of obese patients. Mol Cell Endocrinol 2008; 291: 63-70.

65 Samaras K, Botelho NK, Chisholm DJ, Lord RV. Subcutaneous and visceral adipose tissue gene expression of serum adipokines that predict type 2 diabetes. Obesity 2010; 18: 884-889.

66 Alvehus M, Burén J, Sjöström M, Goedecke J, Olsson T. The human visceral fat depot has a unique inflammatory profile. Obesity 2010; 18 879-883.

67 Xu A, Vanhoutte PM. Adiponectin and adipocyte fatty acid binding protein in the pathogenesis of cardiovascular disease. Am J Physiol Heart Circ Physiol 2012; 302: H1231-H1240.

68 Kadowaki T, Yamauchi T, Kubota N, Hara K, Ueki K, Tobe K. Adiponectin and adiponectin receptors in insulin resistance, diabetes, and the metabolic syndrome. J Clin Invest 2006; 116: 1784-1792.

69 Altintas MM, Azad A, Nayer B, Contreras G, Zaias J, Faul C et al. Mast cells, macrophages, and crown-like structures distinguish subcutaneous from visceral fat in mice. J Lipid Res 2011; 52: 480-488.

70 Bashan N, Dorfman K, Tarnovscki T, Harman-Boehm I, Liberty IF, Blüher $\mathrm{M}$ et al. Mitogen-activated protein kinases, inhibitory-kB kinase, and insulin signaling in human omental versus subcutaneous adipose tissue in obesity. Endocrinology 2007; 148: 2955-2962.

71 Fernández-Veledo S, Vila-Bedmar R, Nieto-Vazquez I, Lorenzo M. c-Jun $\mathrm{N}$-terminal kinase $1 / 2$ activation by tumor necrosis factor- $\alpha$ induces insulin resistance in human visceral but not subcutaneous adipocytes: reversal by liver X receptor agonists. J Clin Endocrinol Metab 2009; 94: 3583-3593.

72 Yamamoto Y, Gesta S, Lee KY, Tran TT, Saadatirad P, Kahn CR. Adipose depots possess unique developmental gene signatures. Obesity 2010; 18 872-878.

73 Chau Y-Y, Bandiera R, Serrels A, Martínez-Estrada OM, Qing W, Lee M et al. Visceral and subcutaneous fat have different origins and evidence supports a mesothelial source. Nat Cell Biol 2014; 16: 367-375.

74 Loh NY, Neville MJ, Marinou K, Hardcastle SA, Fielding BA, Duncan EL et al. LRP5 regulates human body fat distribution by modulating adipose progenitor biology in a dose-and depot-specific fashion. Cell Metab 2015; 21: 262-272.

75 Palsgaard J, Emanuelli B, Winnay JN, Sumara G, Karsenty G, Kahn CR. Cross-talk between Insulin and Wnt signaling in preadipocytes: role of wnt co-receptor low density lipoprotein receptor-related protein-5 (LRP5). J Biol Chem 2012; 287: 12016-12026.

76 Kleppe R, Martinez A, Døskeland SO, Haavik J. The 14-3-3 proteins in regulation of cellular metabolism. Semin Cell Dev Biol 2011; 22: 713-719.
77 Lim GE, Albrecht T, Piske M, Sarai K, Lee JT, Ramshaw HS et al. 14-3-3 [zeta] coordinates adipogenesis of visceral fat. Nat Commun 2015; 6: 7671 .

78 Hilton C, Neville M, Karpe F. MicroRNAs in adipose tissue: their role in adipogenesis and obesity. Int J Obes (Lond) 2013; 37: 325-332.

79 Romao JM, Jin W, He M, McAllister T. Altered microRNA expression in bovine subcutaneous and visceral adipose tissues from cattle under different diet. PLOS ONE 2012; 7: e40605.

80 Heneghan H, Miller N, McAnena O, O'Brien T, Kerin M. Differential miRNA expression in omental adipose tissue and in the circulation of obese patients identifies novel metabolic biomarkers. J Clin Endocrinol Metab 2011; 96: E846-E850.

81 Kloting N, Berthold S, Kovacs P, Schon M, Fasshauer M, Ruschke K et al. MicroRNA expression in human omental and subcutaneous adipose tissue. PLOS ONE 2009; 4: e4699.

82 Wilson RC, Doudna JA. Molecular mechanisms of RNA interference. Annu Rev Biophys 2013; 42: 217-239.

83 Mori MA, Raghavan P, Thomou T, Boucher J, Robida-Stubbs S, Macotela $Y$ et al. Role of microRNA processing in adipose tissue in stress defense and longevity. Cell Metab 2012; 16: 336-347.

84 Mori MA, Thomou T, Boucher J, Lee KY, Lallukka S, Kim JK et al. Altered miRNA processing disrupts brown/white adipocyte determination and associates with lipodystrophy. J Clin Invest 2014; 124: 3339.

85 Joe AWB, Lin Y, Even Y, Vogl AW, Rossi FMV. Depot-specific differences in adipogenic progenitor abundance and proliferative response to highfat diet. Stem Cells 2009; 27: 2563-2570.

86 Wang QA, Tao C, Gupta RK, Scherer PE. Tracking adipogenesis during white adipose tissue development, expansion and regeneration. Nat Med 2013; 19: 1338-1344.

87 Jeffery E, Church CD, Holtrup B, Colman L, Rodeheffer MS. Rapid depot-specific activation of adipocyte precursor cells at the onset of obesity. Nat Cell Biol 2015; 17: 376-385.

88 Macotela Y, Emanuelli B, Mori MA, Gesta S, Schulz TJ, Tseng YH et al. Intrinsic differences in adipocyte precursor cells from different white fat depots. Diabetes 2012; 61: 1691-1699.

89 Wamil M, Battle JH, Turban S, Kipari T, Seguret D, de Sousa Peixoto R et al. Novel fat depot-specific mechanisms underlie resistance to visceral obesity and inflammation in 11ß-hydroxysteroid dehydrogenase type 1-deficient mice. Diabetes 2011; 60: 1158-1167.

90 Konrad D, Rudich A, Schoenle EJ. Improved glucose tolerance in mice receiving intraperitoneal transplantation of normal fat tissue. Diabetologia 2007; 50: 833-839.

91 Hocking SL, Chisholm DJ, James DE. Studies of regional adipose transplantation reveal a unique and beneficial interaction between subcutaneous adipose tissue and the intra-abdominal compartment. Diabetologia 2008; 51: 900-902.

92 Tran TT, Yamamoto Y, Gesta S, Kahn CR. Beneficial effects of subcutaneous fat transplantation on metabolism. Cell Metab 2008; 7: 410-420.

93 Foster M, Shi H, Softic S, Kohli R, Seeley R, Woods S. Transplantation of non-visceral fat to the visceral cavity improves glucose tolerance in mice: investigation of hepatic lipids and insulin sensitivity. Diabetologia 2011; 54: 2890-2899.

94 Foster MT, Softic S, Caldwell J, Kohli R, deKloet AD, Seeley RJ. Subcutaneous adipose tissue transplantation in diet-induced obese mice attenuates metabolic dysregulation while removal exacerbates it. Physiol Rep 2013; 1: e00015.

95 Foster MT, Shi H, Seeley RJ, Woods SC. Transplantation or removal of intra-abdominal adipose tissue prevents age-induced glucose insensitivity. Physio Behav 2010; 101: 282-288.

96 Colombo C, Cutson JJ, Yamauchi T, Vinson C, Kadowaki T, Gavrilova O et al. Transplantation of adipose tissue lacking leptin is unable to reverse the metabolic abnormalities associated with lipoatrophy. Diabetes 2002; 51: 2727-2733.

97 Wentworth JM, Naselli G, Brown WA, Doyle L, Phipson B, Smyth GK et al. Pro-inflammatory CD11c+CD206+ adipose tissue macrophages are associated with insulin resistance in human obesity. Diabetes 2010; 59: 1648-1656.

98 Salmond RJ, Filby A, Qureshi I, Caserta S, Zamoyska R. T-cell receptor proximal signaling via the Src-family kinases, Lck and Fyn, influences T-cell activation, differentiation, and tolerance. Immunol Rev 2009; 228: 9-22. 
99 Yamada E, Pessin JE, Kurland IJ, Schwartz GJ, Bastie CC. Fyn-dependent regulation of energy expenditure and body weight is mediated by tyrosine phosphorylation of LKB1. Cell Metab 2010; 11: 113-124.

100 Lee T-WA, Kwon H, Zong H, Yamada E, Vatish M, Pessin JE et al. Fyn deficiency promotes a preferential increase in subcutaneous adipose tissue mass and decreased visceral adipose tissue inflammation. Diabetes 2013; 62: 1537-1546.

101 Krausgruber T, Blazek K, Smallie T, Alzabin S, Lockstone H, Sahgal N et al. IRF5 promotes inflammatory macrophage polarization and TH1-TH17 responses. Nat Immunol 2011; 12: 231-238.

102 Bertola A, Ciucci T, Rousseau D, Bourlier V, Duffaut C, Bonnafous S et al. Identification of adipose tissue dendritic cells correlated with obesityassociated insulin-resistance and inducing Th17 responses in mice and patients. Diabetes 2012; 61: 2238-2247.

103 Dalmas E, Toubal A, Alzaid F, Blazek K, Eames HL, Lebozec K et al. Irf5 deficiency in macrophages promotes beneficial adipose tissue expansion and insulin sensitivity during obesity. Nat Med 2015; 21: 610-618.

104 Kim HS, Ullevig SL, Nguyen HN, Vanegas D, Asmis R. Redox regulation of 14-3-3 c controls monocyte migration. Arterioscler Thromb Vasc Biol 2014; 34: 1514-1521.

105 BoseDasgupta S, Moes S, Jenoe P, Pieters J. Cytokine-induced macropinocytosis in macrophages is regulated by $14-3-3 \zeta$ through its interaction with serine-phosphorylated coronin 1. FEBS J 2015; 282: 1167-1181.

106 Kusminski CM, Park J, Scherer PE. MitoNEET-mediated effects on browning of white adipose tissue. Nat Commun 2014; 5: 3962.

107 Kusminski CM, Holland WL, Sun K, Park J, Spurgin SB, Lin Y et al. MitoNEET-driven alterations in adipocyte mitochondrial activity reveal a crucial adaptive process that preserves insulin sensitivity in obesity. Nat Med 2012; 18: 1539-1549.

108 Deng T, Lyon CJ, Minze LJ, Lin J, Zou J, Liu JZ et al. Class II major histocompatibility complex plays an essential role in obesity-induced adipose inflammation. Cell Metab 2013; 17: 411-422.

109 Priceman SJ, Kujawski M, Shen S, Cherryholmes GA, Lee H, Zhang C et al. Regulation of adipose tissue T cell subsets by Stat3 is crucial for diet-induced obesity and insulin resistance. Proc Natl Acad Sci USA 2013; 110: 13079-13084.

110 Kolodin D, van Panhuys N, Li C, Magnuson AM, Cipolletta D, Miller CM et al. Antigen-and cytokine-driven accumulation of regulatory $\mathrm{T}$ cells in visceral adipose tissue of lean mice. Cell Metab 2015; 21: 543-557.

111 Asterholm IW, Tao C, Morley TS, Wang QA, Delgado-Lopez F, Wang ZV et al. Adipocyte inflammation is essential for healthy adipose tissue expansion and remodeling. Cell Metab 2014; 20: 103-118.

112 Sidossis L, Kajimura S. Brown and beige fat in humans: thermogenic adipocytes that control energy and glucose homeostasis. J Clin Invest 2015; 125: 478-486.

113 Seale $\mathrm{P}$, Kajimura S, Yang W, Chin S, Rohas LM, Uldry M et al. Transcriptional control of brown fat determination by PRDM16. Cell Metab 2007; 6: 38-54.

114 Seale P, Conroe HM, Estall J, Kajimura S, Frontini A, Ishibashi J et al. Prdm16 determines the thermogenic program of subcutaneous white adipose tissue in mice. J Clin Invest 2011; 121: 96.

115 Cohen P, Levy JD, Zhang Y, Frontini A, Kolodin DP, Svensson KJ et al. Ablation of PRDM16 and beige adipose causes metabolic dysfunction and a subcutaneous to visceral fat switch. Cell 2014; 156: 304-316.

116 Ohno H, Shinoda K, Spiegelman BM, Kajimura S. PPAR $\gamma$ agonists induce a white-to-brown fat conversion through stabilization of PRDM16 protein. Cell Metab 2012; 15: 395-404.

117 Wu J, Boström P, Sparks LM, Ye L, Choi JH, Giang A-H et al. Beige adipocytes are a distinct type of thermogenic fat cell in mouse and human. Cell 2012; 150: 366-376.

118 Nguyen KD, Qiu Y, Cui X, Goh YPS, Mwangi J, David T et al. Alternatively activated macrophages produce catecholamines to sustain adaptive thermogenesis. Nature 2011; 480: 104-108.

119 Qiu Y, Nguyen KD, Odegaard JI, Cui X, Tian X, Locksley RM et al. Eosinophils and type 2 cytokine signaling in macrophages orchestrate development of functional beige fat. Cell 2014; 157: 1292-1308.

120 Hui X, Gu P, Zhang J, Nie T, Pan Y, Wu D et al. Adiponectin enhances cold-induced browning of subcutaneous adipose tissue via promoting M2 macrophage proliferation. Cell Metab 2015; 22: 279-290.

121 Denzel MS, Scimia M-C, Zumstein PM, Walsh K, Ruiz-Lozano P, Ranscht B. T-cadherin is critical for adiponectin-mediated cardioprotection in mice. J Clin Invest 2010; 120: 4342.
122 Hug C, Wang J, Ahmad NS, Bogan JS, Tsao T-S, Lodish HF. T-cadherin is a receptor for hexameric and high-molecular-weight forms of Acrp30/ adiponectin. Proc Natl Acad Sci USA 2004; 101: 10308-10313.

$123 \mathrm{Kim}$ AY, Park YJ, Pan X, Shin KC, Kwak S-H, Bassas AF et al. Obesity-induced DNA hypermethylation of the adiponectin gene mediates insulin resistance. Nat Commun 2015; 6: 7585.

124 Rupnick MA, Panigrahy D, Zhang C-Y, Dallabrida SM, Lowell BB, Langer $\mathrm{R}$ et al. Adipose tissue mass can be regulated through the vasculature. Proc Natl Acad Sci USA 2002; 99: 10730-10735.

125 Bruemmer D. Targeting angiogenesis as treatment for obesity. Arterioscler Thromb Vasc Biol 2012; 32: 161-162.

126 Miyazawa-Hoshimoto S, Takahashi K, Bujo H, Hashimoto N, Saito Y. Elevated serum vascular endothelial growth factor is associated with visceral fat accumulation in human obese subjects. Diabetologia 2003; 46: 1483-1488.

127 Lyden D, Young AZ, Zagzag D, Yan W, Gerald W, O'Reilly R et al. Id1 and Id3 are required for neurogenesis, angiogenesis and vascularization of tumour xenografts. Nature 1999; 401: 670-677.

128 Cutchins A, Harmon DB, Kirby JL, Doran AC, Oldham SN, Skaflen M et al. Inhibitor of differentiation-3 mediates high fat diet-induced visceral fat expansion. Arterioscler Thromb Vasc Biol 2012; 32: 317-324.

129 Galani C, Schneider H. Prevention and treatment of obesity with lifestyle interventions: review and meta-analysis. Int J Public Health 2007; 52: 348-359.

130 Drew BS, Dixon AF, Dixon JB. Obesity management: update on orlistat. Vasc Health Risk Manag 2007; 3: 817-821.

131 Gloy VL, Briel M, Bhatt DL, Kashyap SR, Schauer PR, Mingrone G et al. Bariatric surgery versus non-surgical treatment for obesity: a systematic review and meta-analysis of randomised controlled trials. Br Med J 2013; 347: 55934

132 Benatti F, Solis M, Artioli G, Montag E, Painelli V, Saito F et al. Liposuction induces a compensatory increase of visceral fat which is effectively counteracted by physical activity: a randomized trial. J Clin Endocrinol Metab 2012; 97: 2388-2395.

133 Festuccia WT, Blanchard P-G, Turcotte V, Laplante M, Sariahmetoglu M, Brindley DN et al. Depot-specific effects of the PPARy agonist rosiglitazone on adipose tissue glucose uptake and metabolism. J Lipid Res 2009; 50: 1185-1194.

134 Berthiaume M, Laplante M, Festuccia W, Gélinas Y, Poulin S, Lalonde J et al. Depot-specific modulation of rat intraabdominal adipose tissue lipid metabolism by pharmacological inhibition of $11 \beta$-hydroxysteroid dehydrogenase type 1. Endocrinology 2007; 148: 2391-2397.

135 Hanssen MJW, Hoeks J, Brans B, van der Lans AAJJ, Schaart G, van den Driessche JJ et al. Short-term cold acclimation improves insulin sensitivity in patients with type 2 diabetes mellitus. Nat Med 2015; 21 : 863-865.

136 Bonet ML, Oliver P, Palou A. Pharmacological and nutritional agents promoting browning of white adipose tissue. Biochim Biophys Acta 2013; 1831: 969-985.

137 Gealekman O, Guseva N, Hartigan C, Apotheker S, Gorgoglione M, Gurav $\mathrm{K}$ et al. Depot-specific differences and insufficient subcutaneous adipose tissue angiogenesis in human obesity. Circulation 2011; 123: 186-194.

138 lacobellis G. Local and systemic effects of the multifaceted epicardial adipose tissue depot. Nat Rev Endocrinol 2015; 11: 363-371.

139 Brown NK, Zhou Z, Zhang J, Zeng R, Wu J, Eitzman DT et al. Perivascular adipose tissue in vascular function and disease: a review of current research and animal models. Arterioscler Thromb Vasc Biol 2014; 34: $1621-1630$.

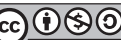

This work is licensed under a Creative Commons Attribution-NonCommercial-ShareAlike 4.0 International License. The images or other third party material in this article are included in the article's Creative Commons license, unless indicated otherwise in the credit line; if the material is not included under the Creative Commons license, users will need to obtain permission from the license holder to reproduce the material. To view a copy of this license, visit http:// creativecommons.org/licenses/by-nc-sa/4.0/ 